\title{
Adsorption of Reactive Brilliant Red X-3B in Aqueous Solutions on Clay-Biochar Composites from Bagasse and Natural Attapulgite
}

\author{
Si Chen ${ }^{1,2}$, Min Zhou ${ }^{1,2}$, Han-Fei Wang ${ }^{1,2}$, Teng Wang ${ }^{1}$, Xiao-Shu Wang ${ }^{1,2}$ (1) , Hao-Bo Hou ${ }^{1,2, *}$ \\ and Bi-Yu Song ${ }^{1, *}$ \\ 1 School of Resource and Environmental Sciences, Wuhan University, Wuhan 430074, China; \\ chensi8683@whu.edu.cn (S.C.); zhoumin@whu.edu.cn (M.Z.); whfnsh1314@163.com (H.-F.W.); \\ 2018001@wtu.edu.cn (T.W.); wangxs.resource@whu.edu.cn (X.-S.W.) \\ 2 Hubei Environmental Remediation Material Engineering Technology Research Center, Wuhan University, \\ Wuhan 430074, China \\ * Correspondence: houhb@whu.edu.cn (H.-B.H.); songby@whu.edu.cn (B.-Y.S.)
}

Received: 27 April 2018; Accepted: 25 May 2018; Published: 29 May 2018

\begin{abstract}
The study aims to determine the adsorption mechanism of reactive brilliant red X-3B (RBR) on a novel low-cost clay-biochar composite with different proportions of bagasse and natural attapulgite (ATP). Pure bagasse, pure ATP, and two mixtures with weight ratios of 1:5 and 1:3 were pyrolyzed at $700{ }^{\circ} \mathrm{C}$ for $4 \mathrm{~h}$ in a muffle furnace. Biochar samples were characterized with an element analyzer and by scanning electron microscopy, X-ray diffraction, Fourier transform infrared, X-ray photoelectron spectroscopy, Brunauer-Emmett-Teller method, and zeta potential measurement. Results of the batch and leaching experiments showed that the adsorption capacities followed the order of 1:3 clay-biochar $>$ 1:5 clay-biochar $>$ bagasse biochar $>$ pure ATP. Furthermore, ATP and bagasse exerted a synergistic effect on the adsorption of RBR. The adsorption data showed good correlation with the Langmuir isotherm, and the kinetic data were fitted to the pseudo-second-order model. The adsorption of RBR on clay-biochar involved electrostatic interaction, hydrogen bond, $\pi-\pi$ interactions, and surface participation. The modification of biochar by ATP improved the adsorption capacity by increasing functional groups and creating adsorption sites. Therefore, ATP-modified clay-biochar composites could be effective adsorbents for the removal of RBR from wastewater.
\end{abstract}

Keywords: reactive brilliant red X-3B; attapulgite; biochar; adsorption

\section{Introduction}

Dyes are widely used in the textile, printing, leather, and gasoline industries. The wastewater from these industries pollutes surface water [1], ground water [2], and even soils through irrigation [3,4]. Reactive brilliant red X-3B (RBR) is an azo dye that is considered stable. Every year, more than 80,000 tons of reactive dyes are consumed; during the synthesis and use of azo dyes, a large amount of environmentally harmful wastewater is produced [5]. Therefore, azo dyes should be removed from wastewater before it is discharged into water bodies.

Compared with other treatment methods, the adsorption method has inherent advantages in dye removal, including low cost, low chemical reagent consumption, few secondary pollution problems, and a high effectiveness level. This technology has also been widely used inorganic and inorganic pollutants in aqueous solutions. The efficiency of dye removal by adsorption mainly depends on the raw materials of the adsorbents used. Activated carbon [6-8], nanoparticles [9,10], plant biomass [11-13], fly ash [14], and natural clay minerals [15,16] have been used to remove dyes. In recent years, biochar has been adopted as an adsorbent for the removal of dyes from aqueous solutions. 
Under limited or no oxygen condition, biomass undergoes thermal decomposition to yield a solid carbon-rich residue referred to as biochar [17-19]. Biochar is an environmentally friendly porous material with a large specific surface area and rich mineral elements [20,21]. Biochar surfaces also comprise oxygen-containing functional groups such as carbonyl group $(-\mathrm{C}=\mathrm{O})$, carboxylate $\left(-\mathrm{COO}^{-}\right)$, and hydroxyl $(-\mathrm{OH})[22,23]$; therefore, biochar can be used as a low-cost adsorbent for removing organic pollutants and heavy metal cations from wastewater [24]. Several studies have examined the use of biochar in the adsorptive removal of organic pollutants, such as pesticides, antibiotics, and dyes, from aqueous solutions [25-27]. However, few studies have focused on the removal of reactive dyes [28-30]. The adsorption mechanism of reactive dyes on biochar remains to be determined.

Attapulgite (ATP) is a naturally fibrillar hydrated magnesium aluminum silicate crystal with moderate cationic exchange capacity, large specific surface area, and reactive hydroxyl groups on the surface; these characteristics of ATP are beneficial to the adsorption of organic compounds from aqueous solutions [31]. Owing to its unique structure, low cost, nontoxicity, and abundance in nature, ATP has been widely regarded as a low-cost alternative adsorbent [32]. To reduce the cost of biochar adsorbents and enhance their sorption capacity for contaminants, scholars have put forward many modification methods to strengthen the adsorption capacity of biochar; these methods include the acid-modified method [33], alkali-modified method [34], and other modification methods [22,35,36]. In two recent studies, minerals were mixed with biomass and then carbonized to adsorb organic contaminants [31,37]. However, to date, no study has explored the use of natural ATP to modify biochar derived from bagasse for enhancing RBR sorption capacity.

In the current work, clay-biochar composites with different ratios of clay and biochar were derived from bagasse and natural ATP by oxygen-limited pyrolysis at $700{ }^{\circ} \mathrm{C}$. The obtained adsorbents, which were labeled as $A B, 1-5-A B, 1-3-A B$, and ATP, were evaluated for their ability to remove RBR from aqueous solutions through batch experiments. The objectives of this study were to evaluate the effect of the synergy between bagasse and ATP on the adsorption of RBR by pyrolysis in an argon atmosphere, to explore the best ratio between biomass and ATP for adsorption, and to probe the adsorption mechanism of RBR on clay-biochar.

\section{Materials and Methods}

\subsection{Reagents}

RBR (CI 18200) with a molecular weight of $615.33 \mathrm{~g} / \mathrm{mol}$ was purchased from Shenshi Chemical Company (Guangzhou, China). The maximum wavelength of the dye is $538 \mathrm{~nm}$. The molecule is negatively charged in water because of the ionization of $\mathrm{Na}^{+}$. Its chemical structure is shown in Figure 1.

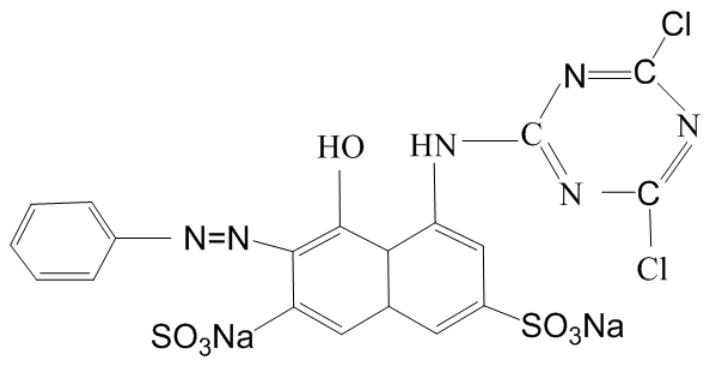

Figure 1. Chemical structure of reactive brilliant red X-3B.

Bagasse was collected from a sugar refinery in Guangxi, China. It was washed thrice and oven-dried overnight at $105{ }^{\circ} \mathrm{C}$. Natural ATP was obtained from Xuyi (Jiangsu, China). Both materials were crushed with a ball crusher and sieved through a $0.25 \mathrm{~mm}$ screen for use in subsequent experiments. 


\subsection{Preparation of Biochar}

ATP and bagasse mixture with a ratio of 1:5 was prepared accordiong to the following process. First, $4 \mathrm{~g}$ of ATP and $20 \mathrm{~g}$ of bagasse powder were poured into a beaker successively. Second, $50 \mathrm{~mL}$ of deionized water was added into the mixture and stirred with a magnetic stirrer to form a paste. Finally, the paste was oven-dried at $105^{\circ} \mathrm{C}$ and milled to powder form. The same procedure was followed for the preparation of the mixed powder with a ratio of 1:3.

Ceramic crucibles were filled up with either pure bagasse powder, ATP, and bagasse mixture with a ratio of 1:5; ATP and bagasse mixture with a ratio of 1:3; or pure ATP powder. The crucibles each had a fitting lid and were pyrolyzed in a muffle furnace in an argon atmosphere. The pyrolysis temperature was raised to $700{ }^{\circ} \mathrm{C}$ at a rate of approximately $7{ }^{\circ} \mathrm{C} / \mathrm{min}$ and held constant for $4 \mathrm{~h}$. The crucibles were then allowed to cool to room temperature. The resulting biochar products were washed with deionized water and oven-dried overnight at $105^{\circ} \mathrm{C}$. Finally, the samples labeled as AB, 1-5-AB, 1-3-AB, and ATP were stored in a closed container for further use in the adsorption experiments.

\subsection{Physical and Chemical Properties of Biochar Samples}

Scanning electron microscopy (SEM, QUANTA, FEI Company, Holland, The Netherlands) analysis was performed on $\mathrm{AB}, 1-5-\mathrm{AB}$, and 1-3-AB to study their surface textures. X-ray diffraction (XRD) was also used to characterize the surface structure. A CHNS/O analyzer (Vario EL cube, Elementar, Langenselbold, Germany) was used to analyze the $\mathrm{C}, \mathrm{H}, \mathrm{N}, \mathrm{S}$, and $\mathrm{O}$ constituents in the samples. The other element constituents were measured by Inductively Coupled Plasma Optical Emission Spectrometry (ICP-OES, PerkinElmer, Waltham, MA, USA) (Prodigy 7). The Brunauer-Emmett-Teller (BET) method (TriStar II 3020 3.02, Micromeritics Instrument Corp., Norcross, GA, USA) was used to measure the specific surface area, total pore volume, and average pore width of the samples. The surface chemical properties of the samples before and after the adsorption of RBR were analyzed by Fourier transform infrared (FTIR) spectroscopy (Nexus, Thermo Nicolet, GMI, Ramsey, NJ, USA), and X-ray photoelectron spectroscopy (XPS) (Thermo ESCALAB 250XI, AVBA Hi-Tech. Services Ltd., HaZafon, Israel).

For the determination of the zeta potential of the biochar samples, $0.005 \mathrm{~g}$ of each sample was placed in a $100 \mathrm{~mL}$ centrifuge tube. Then, $20 \mathrm{~mL}$ of deionized water with or without $0.007 \mathrm{~g}$ RBR was added to each tube. The suspension $\mathrm{pH}$ was adjusted with $\mathrm{NaOH}$ or $\mathrm{HCl}$ within the range of 3.0-9.0. The suspensions were dispersed ultrasonically in a bath-type sonicator at $25^{\circ} \mathrm{C}, 40 \mathrm{kHz}$, and $300 \mathrm{~W}$ for $1 \mathrm{~h}$. After standing for $3 \mathrm{~d}$, the zeta potential values were measured using Malvern Zetasizer Nano ZS (Malvern Instruments Ltd., Malvern, UK). The suspension $\mathrm{pH}$ was determined and used to explore the relationship between the zeta potential and $\mathrm{pH}$.

\subsection{Adsorption Experiments}

The experiments of adsorption isotherms, adsorption kinetic, and the effect of $\mathrm{pH}$ were carried out under the conditions in the Table 1.The concentration of RBR in the filtered suspension was obtained with a UV-Vis spectrometer (UNICAM UV300, Thermo Spectronic, Waltham, MA, USA) at a maximum adsorption wavelength of $538 \mathrm{~nm}$. In the experiments of $\mathrm{pH}$ effect, the solution $\mathrm{pH}$ was adjusted between 3.0 and 9.0 by adding $\mathrm{NaOH}(1 \mathrm{~mol} / \mathrm{L})$ or $\mathrm{HCl}(1 \mathrm{~mol} / \mathrm{L})$ solutions, and the $\mathrm{pH}$ was measured with a $\mathrm{pH}$ meter. The adsorption capacity of biochar for RBR was calculated by

$$
Q_{t}=\frac{V\left(C_{0}-C_{t}\right)}{m}
$$

in which $Q_{t}(\mathrm{mg} / \mathrm{g})$ is the RBR adsorption capacity, $C_{0}(\mathrm{mg} / \mathrm{L})$ is the initial concentration of the RBR solution $(\mathrm{mg} / \mathrm{L}), C_{t}(\mathrm{mg} / \mathrm{L})$ is the RBR concentration at equilibrium, $m(\mathrm{~g})$ is the mass of the biochar used, and $V(\mathrm{~L})$ is the volume of the RBR solution used. 
Table 1. The adsorption experimental runs and conditions.

\begin{tabular}{ccccccc}
\hline $\begin{array}{c}\text { Experimental } \\
\text { Item }\end{array}$ & $\begin{array}{c}\text { Biochar } \\
\text { Weight }(\mathbf{g})\end{array}$ & $\begin{array}{c}\text { RBR Solution Concentrations } \\
(\mathbf{m g} / \mathbf{L})\end{array}$ & Sampling Time (min) & $\begin{array}{c}\text { Temp. } \\
\left({ }^{\circ} \mathbf{C}\right)\end{array}$ & $\begin{array}{c}\text { Vibration } \\
\text { Rate (rpm) }\end{array}$ & SamplingMethod \\
\hline $\begin{array}{c}\text { Adsorption } \\
\text { isotherms }\end{array}$ & 0.1 & $\begin{array}{c}40-200 \\
(40,60,80,100,120,140,160,180,200)\end{array}$ & 1440 & 25 & 150 & $\begin{array}{c}\text { Syringe } \\
\text { membrane }\end{array}$ \\
\hline $\begin{array}{c}\text { Adsorption } \\
\text { kinetics }\end{array}$ & 0.1 & 100 & $\begin{array}{c}5-1440 \\
(5,10,30,60,120,240,720,1440)\end{array}$ & 25 & 150 & $\begin{array}{c}\text { Syringe } \\
\text { membrane }\end{array}$ \\
\hline Effects of $\mathrm{pH}$ & 0.1 & 100 & 1440 & 25 & 150 & $\begin{array}{c}\text { Syringe } \\
\text { membrane }\end{array}$ \\
\hline
\end{tabular}

\section{Results and Discussion}

\subsection{Biochar Properties}

Table 2 presents the characterization of $\mathrm{AB}, 1-5-\mathrm{AB}$, and 1-3-AB. In this study, the BET surface area decreased with increasing ATP content. This outcome is probably due to 1-5-AB and 1-3-AB containing considerable proportions of mineral elements that feature smaller surface areas relative to pure biomass biochar. However, the order of the adsorption capacity was disproportional to the order of the surface area, suggesting that the adsorption for RBR by the as-prepared biochar could mainly depend on chemical adsorption rather than surface participation. Nevertheless, the surface areas of all the samples were still slightly large compared with most of the adsorbable biochar [38]; thus, surface physical adsorption could have played a considerable role. The average pore width increased with increasing ATP content. This outcome could be attributed to the large number of transitional pores $(2-50 \mathrm{~nm})$ of the mineral elements in 1-5-AB and 1-3-AB [39], with 1-3-AB having more mineral elements than 1-5-AB. The order of total pore volume was 1-5-AB $>A B>1-3-A B$. This order is probably due to the added ATP that did not block the pore openings of the biochar sample when the ratio between ATP and bagasse was 1:5. By contrast, the content of ATP was excessive when the ratio between ATP and bagasse was 1:3, such that ATP partially blocked the pore openings of the biochar sample.

Table 2. Basic physical-chemical properties of $A B, 1-5-A B$, and 1-3-AB.

\begin{tabular}{cccc}
\hline Sample & AB & 1-5-AB & 1-3-AB \\
\hline Pore characteristics & & & \\
BET surface area $\left(\mathrm{m}^{2} / \mathrm{g}\right)$ & 219.49 & 178.51 & 63.91 \\
Total pore volume $\left(\mathrm{m}^{3} / \mathrm{g}\right)$ & 0.1270 & 0.1343 & 0.0644 \\
Average pore width $(\mathrm{nm})$ & 2.31 & 3.01 & 4.03 \\
Elemental analysis $(\%)$ & & & \\
$\mathrm{C}$ & 78.27 & 54.76 & 44.96 \\
$\mathrm{H}$ & 0.98 & 0.62 & 0.65 \\
$\mathrm{O}$ & 5.13 & 8.53 & 8.92 \\
$\mathrm{~N}$ & 0.46 & 0.18 & 0.14 \\
$\mathrm{~K}$ & 1.37 & 2.92 & 3.58 \\
$\mathrm{Na}$ & 3.25 & 5.58 & 6.57 \\
$\mathrm{Mg}$ & 0.71 & 1.80 & 2.69 \\
$\mathrm{Al}$ & 0.66 & 2.58 & 3.64 \\
$\mathrm{Fe}$ & 0.75 & 1.77 & 3.04 \\
$\mathrm{Ca}$ & 2.05 & 3.68 & 3.89 \\
$\mathrm{Si}$ & 6.28 & 16.31 & 20.86 \\
\hline
\end{tabular}

The quantitative elemental compositions of $\mathrm{AB}, 1-5-\mathrm{AB}$, and 1-3-AB are listed in Table 1. ATP is a hydrated magnesium aluminum silicate crystal that occurs in nature as a fibrillar mineral; its idealized chemical composition is $\mathrm{Mg}_{5} \mathrm{Si}_{8} \mathrm{O}_{20}(\mathrm{OH})_{2}\left(\mathrm{H}_{2} \mathrm{O}\right)_{4} \cdot 4 \mathrm{H}_{2} \mathrm{O}$. In fact, magnesium ions in crystal structure are often replaced by aluminum ions, iron ions, and sodium ions, and it contains indefinite amounts of $\mathrm{Na}^{+}, \mathrm{Ca}^{2+}, \mathrm{Mg}^{2+}, \mathrm{Al}^{3+}$, and $\mathrm{Fe}^{3+}$ [32]. Therefore, the contents of $\mathrm{Na}, \mathrm{Ca}, \mathrm{Mg}, \mathrm{Al}, \mathrm{Fe}$, and $\mathrm{Si}$ increased with increasing ATP in the current work. The modification increased the $\mathrm{O} / \mathrm{C}$ ratios in $\mathrm{AB}, 1-5-\mathrm{AB}$, 
and $1-3-\mathrm{AB}$ to $0.0825,0.1074$, and 0.1488 , respectively. Hence, the presence of oxygen-containing functional groups on the clay-biochar surfaces increased with increasing ATP. The $[(\mathrm{N}+\mathrm{O}) / \mathrm{C}]$ ratios in $A B, 1-5-A B$, and $1-3-A B$ were $0.0885,0.1108$, and 0.1523 , respectively. The increase in polarity index $[(\mathrm{O}+\mathrm{N}) / \mathrm{C}]$ indicated an increase in the polar functional groups on the surface. This condition likely explains the increase in adsorption capacity.

The potential morphology changes caused by adding different quantities of ATP were explored through the SEM images of the samples (Figure 2a-c). Samples 1-5-AB and 1-3-AB had rougher surfaces than AB did. The SEM images clearly show that some fibrous particles adhered evenly onto both clay-biochar samples, but the density of the fibrous particles was greater on 1-3-AB than on 1-5-AB. No obvious porous structure was observed, and ATP did not cover the pore openings of 1-5-AB. By contrast, some pore openings of 1-3-AB became covered as ATP. Consequently, the BET specific surface area and total volume of the 1-3-AB were lower than those of 1-5-AB.
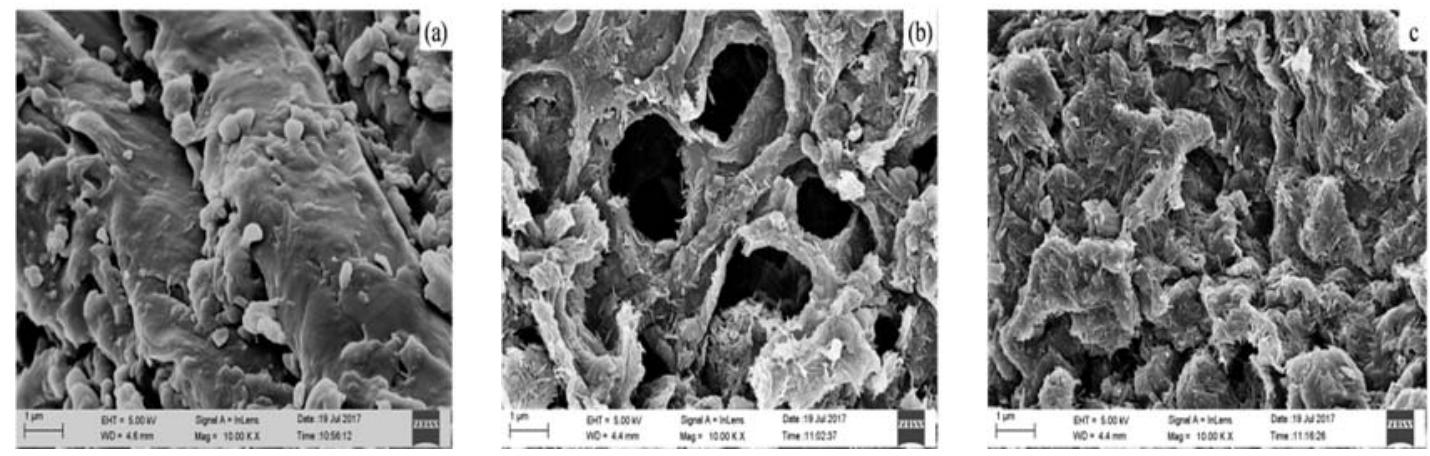

Figure 2. SEM images of the three biochar samples: (a) $\mathrm{AB}$, (b) 1-5-AB, and (c) 1-3-AB.

Figure $3 a-c$ show the XRD spectra of $A B, 1-5-A B$, and 1-3-AB, respectively. No obvious peaks were detected in the spectrum of $\mathrm{AB}$. The main characteristic peaks of $1-5-\mathrm{AB}$ at $2 \theta$ values of 25.578 (0 12 ), 35.154 (1 0 4), 37.779 (1 1 0), 52.556 (0 2 4), 57.507 (1 1 1 6), 66.524 (2 14 4), 68.214 (3 0 0), and 76.888 (1 010 ) were extremely close to the JCPD standards of $\mathrm{Al}_{2} \mathrm{O}_{3}$ (PDF NO. 99-0036). The main characteristic peaks of 1-5-AB at $2 \theta$ values of 21.460 (1 11 1), 26.640 (0 11 1), 35.400 (2 2 0), and 43.722 (2 2 2) were ascribed to $\mathrm{SiO}_{2}$ (PDF NO. 99-0038). The main characteristic peaks of 1-3-AB at $2 \theta$ values of 25.578 (0 1 2), 35.154 (1 0 4), 37.779 (1 1 0), 43.357 (1 1 3 3), 52.556 (0 2 4), 57.507 (1 1 6), 66.524 (2 1 4), 68.214 (3 0 0), and 76.888 (1 0 10) were also close to the JCPD standards of $\mathrm{Al}_{2} \mathrm{O}_{3}$ (PDF NO. 99-0036). The main characteristic peaks of 1-3-AB at $2 \theta$ values of 21.460 (1 111 ) and 35.400 (2 2 0) were ascribed to $\mathrm{SiO}_{2}$ (PDF NO. 99-0038). The characteristic peaks of 1-3-AB at $2 \theta$ values of 20.859 (1 000$)$ and $26.640\left(\begin{array}{lll}0 & 1 & 1\end{array}\right)$ were ascribed to $\mathrm{SiO}_{2}$ (PDF NO. 99-0088). These results indicated that the surfaces of 1-5-AB and 1-3-AB were both mainly covered by $\mathrm{Al}_{2} \mathrm{O}_{3}$ and $\mathrm{SiO}_{2}$. They also suggested that the ATP was successfully loaded onto the surfaces of the biochar. The same results were obtained by SEM.

FTIR is an essential technique for determining the characteristic functional groups on adsorbents. As shown in Figure 4, the peaks at 469 and $1560 \mathrm{~cm}^{-1}$ in 1-5-AB, as well as the peaks at 469 and $1571 \mathrm{~cm}^{-1}$ in 1-3-AB, did not exist in AB. The $469 \mathrm{~cm}^{-1}$ peaks were ascribed to the bend vibration of $\mathrm{Si}-\mathrm{O}-\mathrm{Si}$ [40]. The peaks at 1560 and $1571 \mathrm{~cm}^{-1}$ in the spectra of $1-5-\mathrm{AB}$ and $1-3-\mathrm{AB}$ were ascribed to the $\mathrm{C}=\mathrm{O}$ asymmetric vibration in carboxylate ions $\left(-\mathrm{COO}^{-}\right)[40]$. The above two peaks indicated the production of $\mathrm{Si}-\mathrm{O}-\mathrm{Si}$ and $-\mathrm{COO}^{-}$with the addition of ATP. The production of Si-O-Si and $-\mathrm{COO}^{-}$may explain the improvement of the adsorption capacity of the biochar samples for RBR after ATP-induced modification. The peaks at 1092, 1039, and $1039 \mathrm{~cm}^{-1}$ in the spectra of $A B, 1-5-A B$, and 1-3-AB, respectively, were ascribed to the aliphatic ether $\mathrm{C}-\mathrm{O}$ and alcohol $\mathrm{C}-\mathrm{O}$ stretching [41]. The peaks at 2919,2897 , and $2939 \mathrm{~cm}^{-1}$ in the spectra of $A B, 1-5-A B$, and 1-3-AB, respectively, were attributed to the aliphatic $\mathrm{C}-\mathrm{H}$ stretching [42]. The peaks at 3434, 3442, and $3437 \mathrm{~cm}^{-1}$ in the spectra of $\mathrm{AB}, 1-5-\mathrm{AB}$, and 1-3-AB, respectively, were ascribed to $\mathrm{O}-\mathrm{H}$ stretching [42]. The FTIR spectra of the three biochar 
samples show that $\mathrm{O}-\mathrm{H}, \mathrm{C}-\mathrm{H}$, and $\mathrm{C}-\mathrm{O}$ mainly existed on the surface of $\mathrm{AB}$, whereas $\mathrm{Si}-\mathrm{O}-\mathrm{Si},-\mathrm{COO}^{-}$, $\mathrm{C}-\mathrm{O}, \mathrm{O}-\mathrm{H}$, and $\mathrm{C}-\mathrm{H}$ mainly existed on the surfaces of 1-5-AB and 1-3-AB. All of these functional groups could have provided the adsorption sites for RBR.

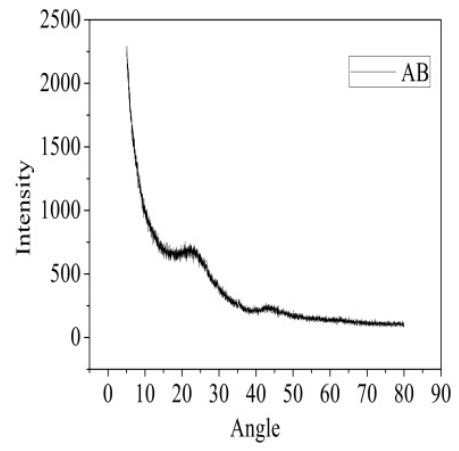

(a)

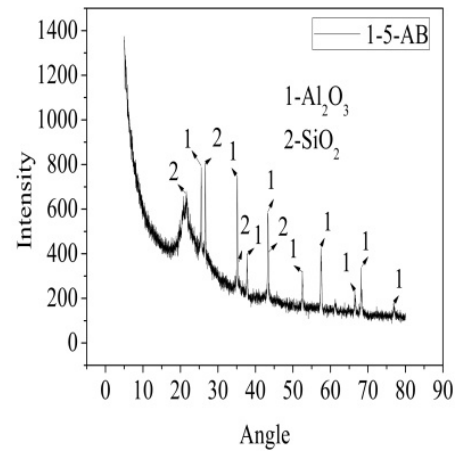

(b)

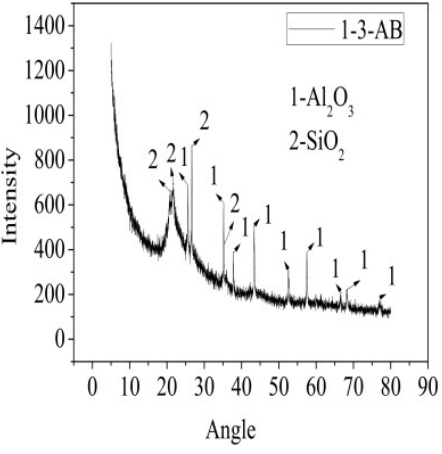

(c)

Figure 3. XRD spectra of the three biochar samples: (a) AB, (b) 1-5-AB, and (c) 1-3-AB.

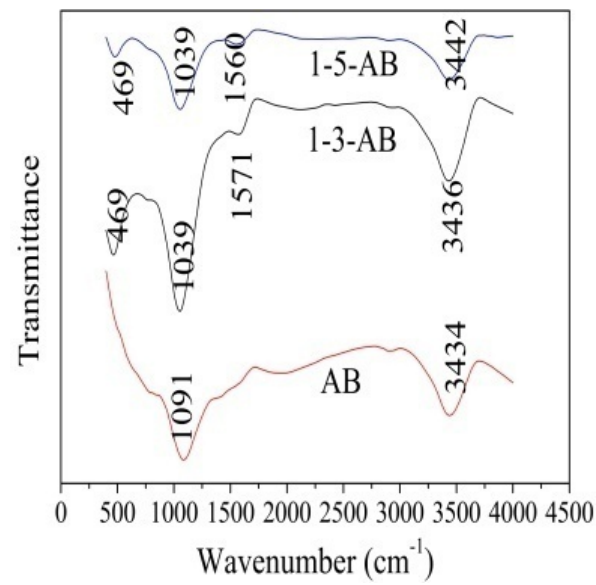

Figure 4. FTIR spectra of the three biochar samples before adsorption of RBR.

\subsection{Effects of $\mathrm{pH}$ on Zeta Potential and the Adsorption of RBR by the Biochar Samples}

Zeta potential describes the electro kinetic potential in colloidal dispersions, and its value is related to the surface charge of such particles. The protonation and deprotonation of functional groups can create a net charge on the surfaces of solid particles, and this surface charge can form an electrical double layer in the solution phase near the surface [43]. In the current work the zeta potential values were measured as a function of the solution $\mathrm{pH}$ for $\mathrm{AB}, 1-5-\mathrm{AB}$, and 1-3-AB (Figure $5 \mathrm{~b}-\mathrm{d}$, respectively). The three biochar samples carried positive charges in the initial stage; as the $\mathrm{pH}$ rose, the charges on their surface became negative.The negative charge of the biochar samples originated from the dissociation of the oxygen-containing groups. Moreover, the increased $\mathrm{pH}$ value was beneficial only to the dissociation of the positive functional groups on the surface. Thus, the surface negative charge of the biochar samples intensified. 


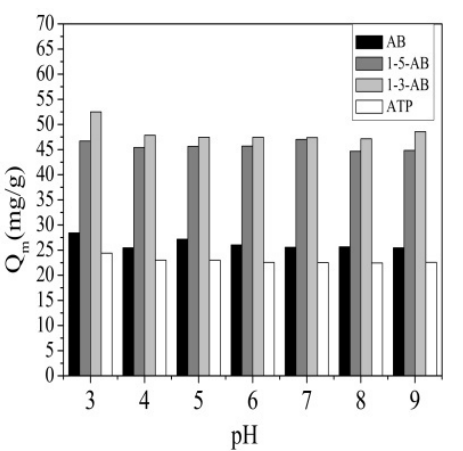

(a)

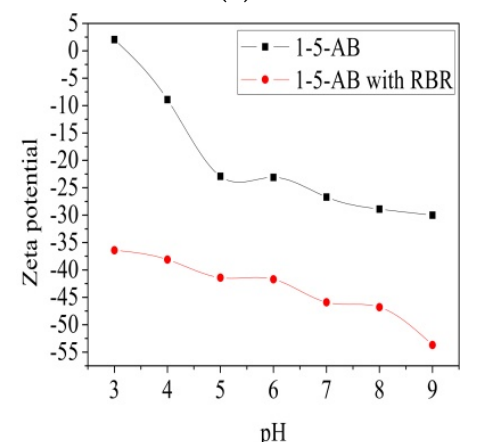

(c)

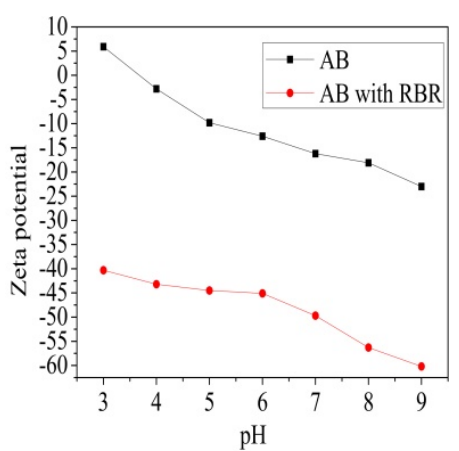

(b)

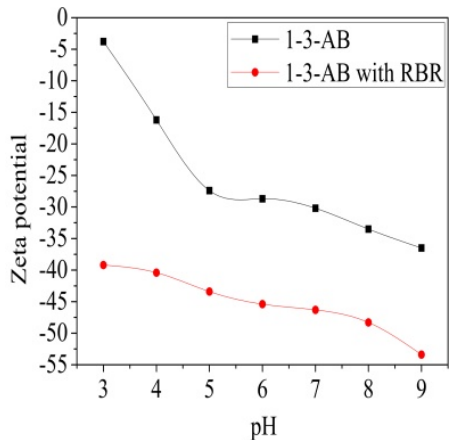

(d)

Figure 5. Effects of initial $\mathrm{pH}$ on the adsorption of RBR on the biochar samples: (a) effect of $\mathrm{pH}$ on the adsorption capacity of the three biochar samples, (b) effect of $\mathrm{pH}$ on the zeta potential of $\mathrm{AB}$, (c) effect of $\mathrm{pH}$ on the zeta potential of 1-5- $\mathrm{AB}$, and (d) effect of $\mathrm{pH}$ on the zeta potential of 1-3-AB.

The electrostatic adsorption of ions by solid charged surfaces does not affect the surface charge and surface potential of colloidal particles, because the adsorbed ions exist in the diffuse layer of the electrical double layers on the particles; however, the intermolecular interaction changes the surface charge and surface potential of colloidal particles, because these ions enter the stern layer of the electrical double layers and form chemical bonds with the surfaces of solid particles [44]. In this study, the presence of RBR shifted the zeta potential-pH curves of the three samples to more negative values, as shown in Figure 5b-d. The zeta potential of the biochar samples with RBR increased with increasing suspension $\mathrm{pH}$. These results indicated that the surface functional groups on the biochar samples formed hydrogen bonds or $\pi-\pi$ interactions with RBR, and the contribution of this form of adsorption increased with increasing suspension $\mathrm{pH}$. After the adsorption of RBR by the three biochar samples, RBR, which carried negative charge, became part of the biochar samples. This process probably made the negative charge of the biochar samples particularly negative. This outcome provides evidence for the intermolecular interaction between dyes and biochar. Although the shift in the zeta potential cannot explain the existence of electrostatic adsorption, electrostatic adsorption is still one of the adsorption mechanisms. When the $\mathrm{pH}$ value was 3.0, the surfaces of $\mathrm{AB}, 1-5-\mathrm{AB}$, and 1-3-AB each carried a positive charge, and RBR, which carried a negative charge on its surface, was adsorbed onto the surfaces of the three samples. Thus, the adsorption capacity was strongest at a $\mathrm{pH}$ value of 3.0 (Figure 5a). When the $\mathrm{pH}$ value increased, the surfaces of $\mathrm{AB}$ and 1-5-AB shifted to a negative charge, and the electrostatic adsorption declined to zero and became electrostatic repulsion; however, the repulsion between the biochar samples and RBR could promote the hydrogen bonding interaction between them [43].

As shown in Figure 5a, the amounts of RBR sorption on the three biochar samples were stable in the initial $\mathrm{pH}$ range of 3.0-9.0, and the variation in the absorption capacity was minimal. Hence, the three biochar samples had a wide $\mathrm{pH}$ range of application and a high RBR removal rate. The increased $\mathrm{pH}$ value was favorable for the chemical adsorption of RBR but unfavorable 
for the electrostatic attraction between the biochar samples and RBR. When the $\mathrm{pH}$ value was 3.0, the three biochar samples had a strong adsorption capacity. The positively charged biochar samples at this $\mathrm{pH}$ value could easily adsorb the negatively charged RBR by electrostatic attraction. $A B$, $1-5-\mathrm{AB}$, and 1-3-AB demonstrated a strong adsorption capacity again at $\mathrm{pH}$ values of 5.0, 7.0, and 9.0. This resurgence in the adsorption capacity could be the result of the combined effects of chemical adsorption and electrostatic interaction.

\subsection{Adsorption Isotherms of RBR by the Biochar Samples}

The biochar samples with different ATP contents demonstrated different adsorption capacities for RBR. Figure 6a shows that 1-3-AB demonstrated the greatest adsorption capacity for RBR, followed by 1-5-AB. AB had the lowest adsorption capacity. This order is generally consistent with the order of the ATP contents of the biochar samples. However, pure ATP had the lowest adsorption capacity, thereby suggesting that the increased adsorption capacity did not depend on the ATP content alone. Bagasse and ATP exerted a synergistic effect on RBR by high temperature pyrolysis in a limited-oxygen environment.

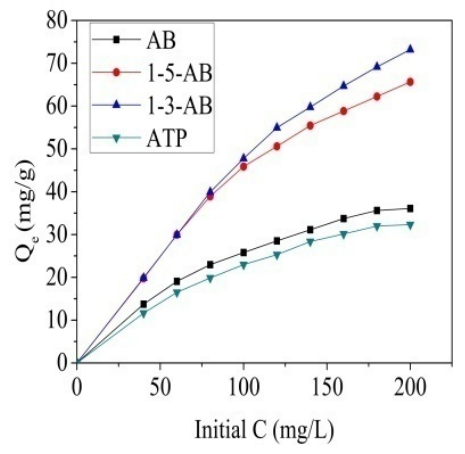

(a)

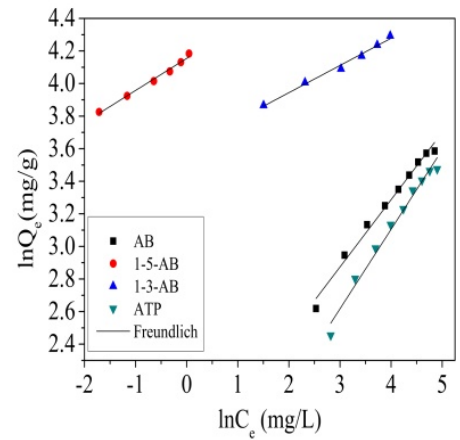

(b)

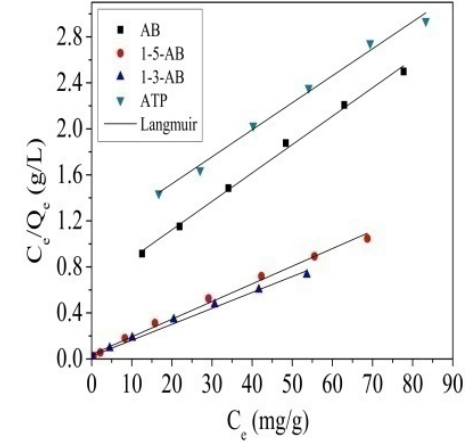

(c)

Figure 6. Sorption isotherms of RBR on the biochar samples: (a) initial concentration vs. sorption capacity of the three biochar samples for RBR, (b) Freundlich isotherm parameter, and (c) Langmuir isotherm parameter (dosage, $0.1 \mathrm{~g}$; temperature, $25^{\circ} \mathrm{C}$; initial concentration, $40-200 \mathrm{mg} / \mathrm{L}$; initial pH, 6.0-7.0).

After the adsorption experiments, the equilibrium solution $\mathrm{pH}$ values were measured. The solutions were alkaline, and the equilibrium solution $\mathrm{pH}$ values for $\mathrm{AB}, 1-5-\mathrm{AB}$, and 1-3- $\mathrm{AB}$ were in the ranges of 7.17-7.45, 8.36-9.02, and 8.79-9.19, respectively. Alkaline $\mathrm{pH}$ is favorable for chemical attraction but unfavorable for electrostatic attraction. The negative charge of the biochar samples originated from the dissociation of their oxygen-containing groups. Thus, the negative charge intensified with increased $\mathrm{pH}$. As a result, the chemical attraction improved, whereas the electrostatic attraction weakened.

Two common isotherm equations were used to describe the process of the experimental isotherms. The Langmuir model describes the monolayer sorption of a target compound on a homogenous surface, whereas the Freundlich model explains a multilayer adsorption process [45].

Langmuir isotherm:

$$
\frac{1}{\mathrm{Q}_{e}}=\frac{1}{K_{L} \mathrm{Q}_{m} C_{e}}+\frac{1}{\mathrm{Q}_{m}}
$$

Freundlich isotherm:

$$
\mathrm{Q}_{e}=K_{F} C_{e}^{n}
$$

in which $Q_{m}$ denotes the Langmuir maximum capacity, $C_{e}$ is the equilibrium concentration of RBR in the solution, $Q_{e}$ is the amount of dye adsorbed at equilibrium, $K_{L}$ represents the Langmuir bonding 
term related to the interaction energies, $K_{F}$ represents the Freundlich affinity coefficient, and $n$ is the Freundlich linearity constant.

Figure $6 \mathrm{~b}, \mathrm{c}$ shows that the simulation of the Langmuir model fitted the isotherms effectively, as confirmed in the results presented in Table 3. The Langmuir isotherm indicated that the adsorption process was attributable to the surface coverage and the formation of a monolayer when the surface of the adsorbent reached saturation [33]. The results showed that the monolayer adsorption capacities of $\mathrm{AB}, 1-5-\mathrm{AB}$, and 1-3-AB were dominant. The maximum sorption capacity from the Langmuir equation may be useful for comparing the RBR sorption capacities of the three biochar samples. The maximum adsorption capacities of AB, 1-5-AB, 1-3-AB, and ATP were 40.50, 65.15, 72.20, and $42.59 \mathrm{mg} / \mathrm{g}$, respectively. Apparently, these results confirmed that the modification by ATP enhanced the sorption capacity of the biochar samples for RBR in an aqueous solution. Notably, the $K_{L}$ values of 1-5-AB and 1-3-AB were higher than those of $A B$, thereby indicating the formation of new functional groups on the surfaces of 1-5-AB and 1-3-AB as a result of the high adsorption energy. $K_{L}$ of 1-3-AB was higher than that of 1-5-AB, suggesting that $K_{L}$ was related to the content of ATP.

Table 3. Isotherm parameters for the adsorption of RBR.

\begin{tabular}{ccccccc}
\hline \multirow{2}{*}{$\begin{array}{c}\text { Biochar } \\
\text { Samples }\end{array}$} & \multicolumn{3}{c}{ Langmuir } \\
\cline { 2 - 7 } & $\boldsymbol{Q}_{\boldsymbol{m}} \mathbf{( \mathbf { m g } / \mathbf { g } )}$ & $\boldsymbol{K}_{\boldsymbol{L}}(\mathbf{L} / \mathbf{m g})$ & $\mathbf{R}^{\mathbf{2}}$ & $\left.\boldsymbol{K}_{\boldsymbol{F}}(\mathbf{m g} \mathbf{g} \mathbf{( m g} / \mathbf{L})^{\mathbf{1} / \boldsymbol{n}}\right)$ & $\boldsymbol{n}$ & $\mathbf{R}^{\mathbf{2}}$ \\
\hline $\mathrm{AB}$ & 40.50 & 0.039 & 0.995 & 1.512 & 0.413 & 0.986 \\
$1-5-\mathrm{AB}$ & 65.15 & 0.401 & 0.993 & 1.218 & 0.197 & 0.988 \\
$1-3-\mathrm{AB}$ & 72.20 & 0.581 & 0.992 & 1.182 & 0.167 & 0.988 \\
$\mathrm{ATP}$ & 42.59 & 0.022 & 0.991 & 1.629 & 0.488 & 0.981 \\
\hline
\end{tabular}

Table 4 compares the maximum adsorption capacities of $\mathrm{AB}, 1-5-\mathrm{AB}$, and 1-3-AB with different types of adsorbents previously reported [46-52] for the removal of RBR. The experimental maximum adsorption capacity $\left(Q_{m, e x p}\right)$ of RBR on 1-3-AB was moderate compared with previously reported adsorbents. Nevertheless, it is low-cost and environmentally friendly. Thus, 1-3-AB is an efficient adsorbent material for the removal of RBR from aqueous solutions.

Table 4. Comparison of the maximum adsorption capacities $\left(Q_{m}\right)$ of RBR on different absorbents.

\begin{tabular}{ccc}
\hline Adsorbent & $\left.Q_{m} \mathbf{( m g} / \mathbf{g}\right)$ & Ref. \\
\hline $\mathrm{AB}$ & 40.5 & This study \\
$1-5-\mathrm{AB}$ & 65.1 & This study \\
1-3-AB & 72.2 & This study \\
$\mathrm{CB}[6]$ & 158.5 & {$[45]$} \\
$\mathrm{Py}-\mathrm{MS}$ & 891.1 & {$[46]$} \\
$\mathrm{MFe}_{3} \mathrm{O}_{4} /$ CsNPS & 476.8 & {$[47]$} \\
$\mathrm{NiO}$ nanosheets & 30.4 & {$[48]$} \\
$\mathrm{MgO}$ nanoplates & 303.0 & {$[49]$} \\
Organic aerogels & 90.0 & {$[50]$} \\
Carbon aerogels & 450.0 & {$[50]$} \\
$\mathrm{Ni} / \mathrm{Al}-\mathrm{LDH}$ & 4.9 & {$[51]$} \\
$\mathrm{Mg} / \mathrm{Al}-\mathrm{LDH}$ & 3.8 & {$[51]$} \\
$\mathrm{Co} / \mathrm{Al}-\mathrm{LDH}$ & 2.3 & {$[51]$} \\
\hline
\end{tabular}

\subsection{Adsorption Kinetics}

The RBR adsorption capacities of $\mathrm{AB}, 1-5-\mathrm{AB}$, and 1-3-AB at different times are shown in Figure 7a. The RBR adsorption capacity increased rapidly within the first 240-300 $\mathrm{min}$, then slowly stabilized until the adsorption equilibrium was reached after $24 \mathrm{~h}$. 


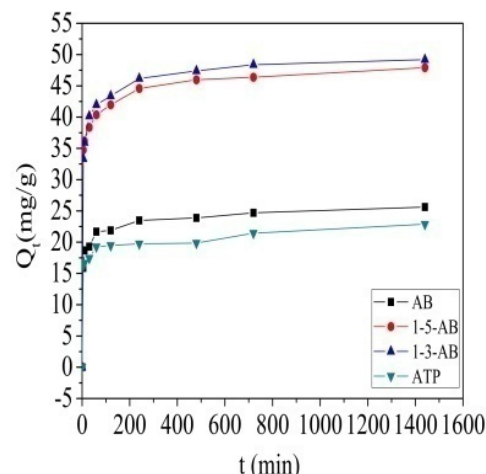

(a)

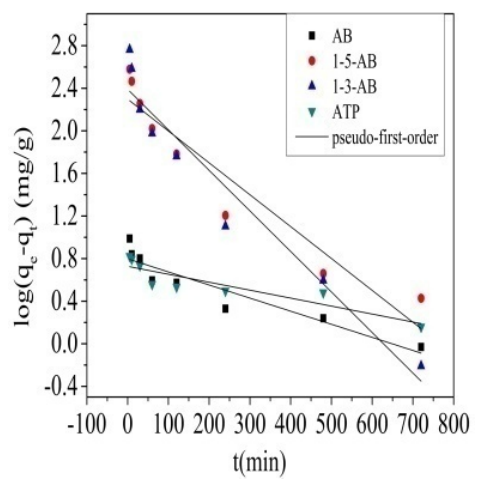

(b)

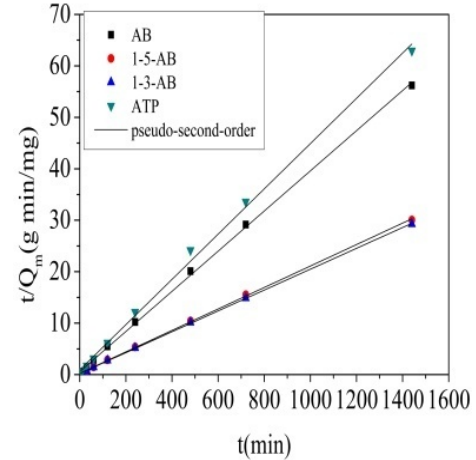

(c)

Figure 7. Kinetics spectra for the sorption of RBR on the three biochar samples: (a) effect of contact time on RBR adsorption capacity of the biochar samples, (b) pseudo-first-order model, and (c) pseudo-second-order model (biochar dosage, $0.1 \mathrm{~g}$; temperature, $25^{\circ} \mathrm{C}$; $t, 1440 \mathrm{~min}$; initial $\mathrm{pH}$, 6.0-7.0).

For the determination of the controlling mechanism of the RBR adsorption process of the three biochar samples, the pseudo-first-order kinetic model and pseudo-second-order kinetic model were applied to simulate the dynamic experimental data.

Pseudo-first-order kinetic model:

$$
\ln \left(q_{e}-q_{t}\right)=\ln q_{e}-k_{1} t
$$

Pseudo-second-order kinetic model:

$$
\frac{t}{q_{t}}=\frac{1}{k_{2} q_{e}^{2}}+\frac{t}{q_{e}}
$$

in which $q_{e}$ and $q_{t}(\mathrm{mg} / \mathrm{g})$ are the amounts of RBR absorbed onto the solid phase at equilibrium and at time $t$, respectively; $k_{1}\left(\mathrm{~min}^{-1}\right)$ is the rate constant of the pseudo-first-order adsorption model; and $k_{2}$ $[\mathrm{g} /(\mathrm{mg} \mathrm{min})]$ is the rate constant of the pseudo-second-order adsorption model.

The values of calculated $q_{e}\left(q_{e, c a l}\right), k_{1}, k_{2}$, correlation coefficient $\left(\mathrm{r}^{2}\right)$, and experimental $q_{e}\left(q_{e, \exp }\right)$ are listed in Table 5, which shows that the pseudo-second-order model fitted the adsorption process effectively. The plots of the pseudo-first-order model and pseudo-second-order model for RBR adsorption on $A B, 1-5-A B$, and 1-3-AB are shown in Figure $7 b, c$.

Table 5. Pseudo-first-order and pseudo-second-order constants and correlation coefficients for the adsorption of RBR on the biochar samples.

\begin{tabular}{lcccc}
\hline $\begin{array}{l}\text { Kinetic } \\
\text { Models }\end{array}$ & AB & 1-5-AB & 1-3-AB & ATP \\
\hline$q_{e, \text { exp }}(\mathrm{mg} / \mathrm{g})$ & 25.619 & 47.911 & 49.195 & 22.876 \\
\hline Pseudo-first-order & & & & \\
\hline$q_{e, \text { cal }}(\mathrm{mg} / \mathrm{g})$ & 2.222 & 9.956 & 10.916 & 2.207 \\
$k_{1}\left(\mathrm{~min}^{-1}\right)$ & 0.001 & 0.002 & 0.004 & 0.001 \\
$\mathrm{r}^{2}$ & 0.858 & 0.895 & 0.931 & 0.792 \\
\hline Pseudo-second-order & 25.63 & 47.94 & 49.33 & \\
\hline$q_{e, \text { cal }}(\mathrm{mg} / \mathrm{g})$ & 0.04 & 0.002 & 0.002 & 0.002 \\
$k_{2}(\mathrm{~g} / \mathrm{mg}$ & 0.999 & 0.999 & 0.999 & 0.996 \\
$\mathrm{~min})$ & & & & \\
$\mathrm{r}^{2}$ & & & & \\
\hline
\end{tabular}


The pseudo-second-order model fitted the sorption data on $\mathrm{AB}, 1-5-\mathrm{AB}$, and 1-3-AB satisfactorily with high correlation coefficients $\left(\mathrm{r}^{2} \geq 0.996\right)$. The calculated data are in good agreement with the experimental data, as shown in Table 4. The pseudo-second-order model posits that the mechanism of the adsorption of adsorbates on an adsorbent is the rate-limiting step [53]. The rate-limiting step may be a chemical reaction or chemisorption process, which involves valence forces by sharing or exchanging electrons between biochar and RBR [54]. Therefore, RBR could have been adsorbed onto the surfaces of $\mathrm{AB}, 1-5-\mathrm{AB}$, and 1-3- $\mathrm{AB}$ by chemical interaction, and this process required a relatively long period to reach equilibrium.

\subsection{Regeneration of Adsorbents}

The consecutive adsorption processes were performed five times to evaluate the reuse value of the samples. A methanol solution was used as the washing agent. RBR adsorbed onto the adsorbent was extracted by a three-stage washing procedure in which $10 \mathrm{~mL}$ of methanol was used [45]. Figure 8 shows the relationship between the number of treatment repetitions and the RBR adsorption capacity of $A B, 1-5-A B$, and 1-3-AB. The adsorption capacity of $A B$ decreased along with the increase in the correct term. However, the adsorption capacities of 1-5-AB and 1-3-AB were stable. In addition, the RBR removal percentages of $1-5-\mathrm{AB}$ were $83.6 \%, 86.5 \%, 84.7 \%, 85.2 \%$, and $83.7 \%$ for the first to fifth regeneration. The RBR removal percentages of $1-3-\mathrm{AB}$ were $86.7 \%, 85.3 \%, 87.4 \%, 85.2 \%$, and $86.1 \%$ for the first to fifth regeneration. These results show that 1-5-AB and 1-3-AB could be successfully regenerated and reused.

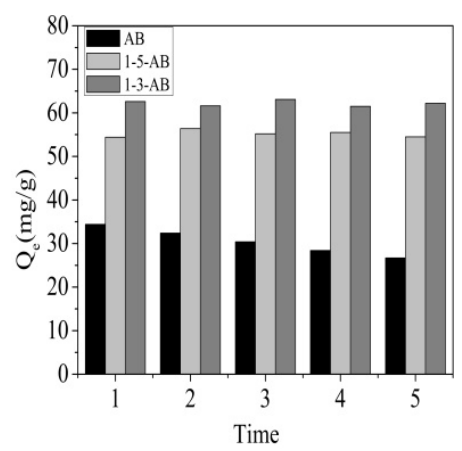

Figure 8. Regeneration cycle performance of $\mathrm{AB}, 1-5-\mathrm{AB}$, and 1-3-AB.

\subsection{Adsorption Mechanisms}

The difference between the FTIR spectra before and after the adsorption of RBR was obtained to monitor the variations in the vibrations of the surface functional groups. Figure 9 shows that the stretching vibration of $\mathrm{C}-\mathrm{O}\left(1099,1039\right.$, and $\left.1039 \mathrm{~cm}^{-1}\right)$ in the three biochar samples, the $\mathrm{C}=\mathrm{O}$ asymmetric vibration in carboxylate ions $\left(-\mathrm{COO}^{-}\right)$in the spectra of 1-5- $\mathrm{AB}$ and 1-3-AB (1560 and $\left.1572 \mathrm{~cm}^{-1}\right)$, the aliphatic C-H stretching $\left(2919,2897\right.$, and $\left.2939 \mathrm{~cm}^{-1}\right)$ in the spectra of the three biochar samples, and the $\mathrm{O}-\mathrm{H}$ stretching $\left(3434,3442\right.$, and $\left.3437 \mathrm{~cm}^{-1}\right)$ in the spectra of the three biochar samples all changed, with the absorption peak positions of $\mathrm{O}-\mathrm{H}$ in 1-5- $\mathrm{AB}$ and 1-3-AB demonstrating the most remarkable change. The changes in these peak positions corresponded to the bond energy change, revealing the important role of $\pi-\pi$ interactions and hydrogen bonding formation between RBR and biochar in the adsorption process. 


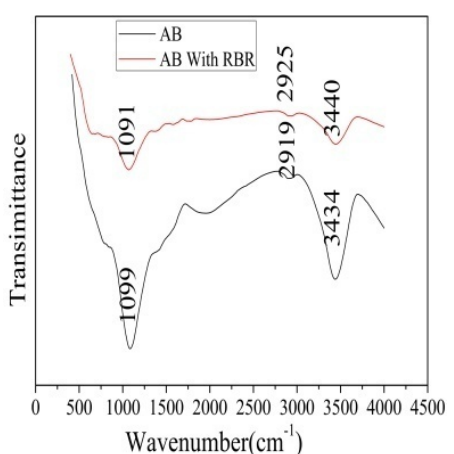

(a)

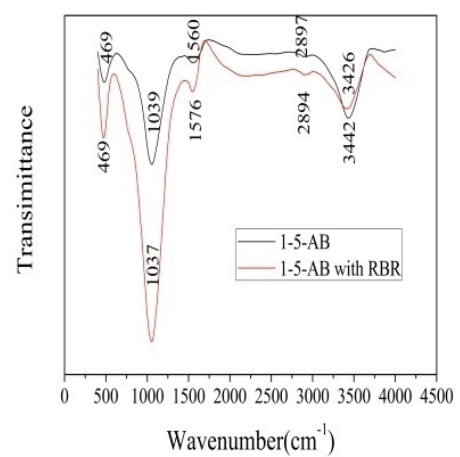

(b)

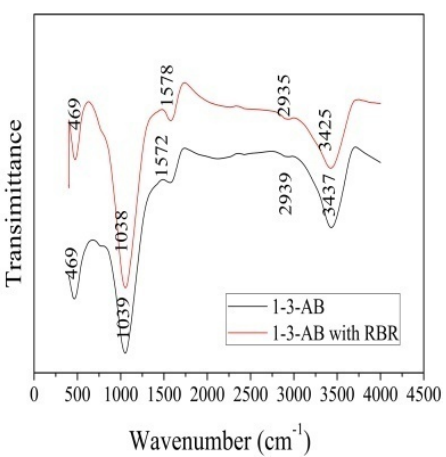

(c)

Figure 9. FTIR spectra of the biochar samples before and after the adsorption of RBR: (a) AB before and after the adsorption of RBR, (b) 1-5-AB before and after the adsorption of RBR, and (c) 1-3-AB before and after the adsorption of RBR.

Because the adsorption mechanism of the three biochar samples were nearly the same according to the infrared analysis, the XPS spectra of 1-5-AB before and after adsorption of RBR were detected as a typical sample. The spectra present two distinct peaks, due to carbon ( $\mathrm{C} 1 \mathrm{~s})$ and oxygen $(\mathrm{O} 1 \mathrm{~s})$. As shown in Figure 10a, the peak around $284.6 \mathrm{eV}$ is attributed to $\mathrm{C} 1 \mathrm{~s}$, and the spectra have been resolved into three individual component peaks, namely, the following: (1) graphitic, aromatic $(\mathrm{C}-\mathrm{C})$; (2) $\mathrm{C}$ in hydroxyl, ethers $(\mathrm{C}-\mathrm{OH}, \mathrm{C}-\mathrm{O}-\mathrm{C})$; (3) $\mathrm{C}$ in carbonyl $(\mathrm{C}=\mathrm{O})$. On the other hand, the peak around $531.8 \mathrm{eV}$ is attributed to $\mathrm{O} 1 \mathrm{~s}$, as illustrated in Figure 10b; the high-resolution $\mathrm{O}$ 1s spectra showed the presence of 2 peaks: (1) oxygen atoms in hydroxyl or ethers ( $\mathrm{C}-\mathrm{OH}, \mathrm{C}-\mathrm{O}-\mathrm{C})$; (2) oxygen in anhydride, lactone, or carboxylic acids $\left(\mathrm{COO}^{-}\right)$[55]. The content of $\mathrm{C}$ and $\mathrm{O}$ in every chemical valence state changed after adsorption of RBR by calculating the peak areas. Additionally, the peak positions shifted after adsorption, illustrating $\mathrm{C}-\mathrm{C}, \mathrm{C}-\mathrm{OH}, \mathrm{C}-\mathrm{O}-\mathrm{C}, \mathrm{C}=\mathrm{O}$, and $\mathrm{COO}^{-}$interacted with functional group in the RBR by hydrogen bonding or $\pi-\pi$ interactions, which confirms the results of the infrared analysis once again.

The effect of $\mathrm{pH}$ (Figure 5a) indicated that electrostatic attraction also played an important role in the adsorption of RBR on biochar in a highly acidic environment, whereas electrostatic repulsion, which promoted the hydrogen bond between dye and biochar, was dominant in a low acidic and alkaline environment. As shown in Table 1, the three biochar samples were porous materials with large surface areas. Thus, the molecules of the dye could have participated in the physical adsorption on the biochar samples.

As a result, the mechanisms of adsorption for RBR on the adsorbents may be attributed to the electrostatic attraction/repulsion between RBR and biochar, hydrogen bonding formation, hydrophobic interaction, $\pi-\pi$ electron-donor-acceptor, and surface participation [38]. Previous studies revealed that the enhancement of organic pollutant adsorption by biochar is mainly attributed to the oxygen-containing functional groups that interact with organic pollutants via hydrogen binding and complexation [42,56]. After a series of characterization analyses, namely, SEM, FTIR, zeta potential, and XRD, the results showed that the ATP-modified clay-biochar composites contained more $\mathrm{Al}_{2} \mathrm{O}_{3}$ and $\mathrm{SiO}_{2}$ particles, as well as oxygen-containing functional groups on the surface, compared with pure bagasse biochar. Furthermore, RBR molecules may form a hydrogen bond with the functional groups as acceptors or donors. The $\mathrm{Al}_{2} \mathrm{O}_{3}$ and $\mathrm{SiO}_{2}$ particles could serve as the adsorption sites for RBR in aqueous solutions. As a result, the ATP modification greatly enhanced the sorption capacity of bagasse biochar for RBR. 

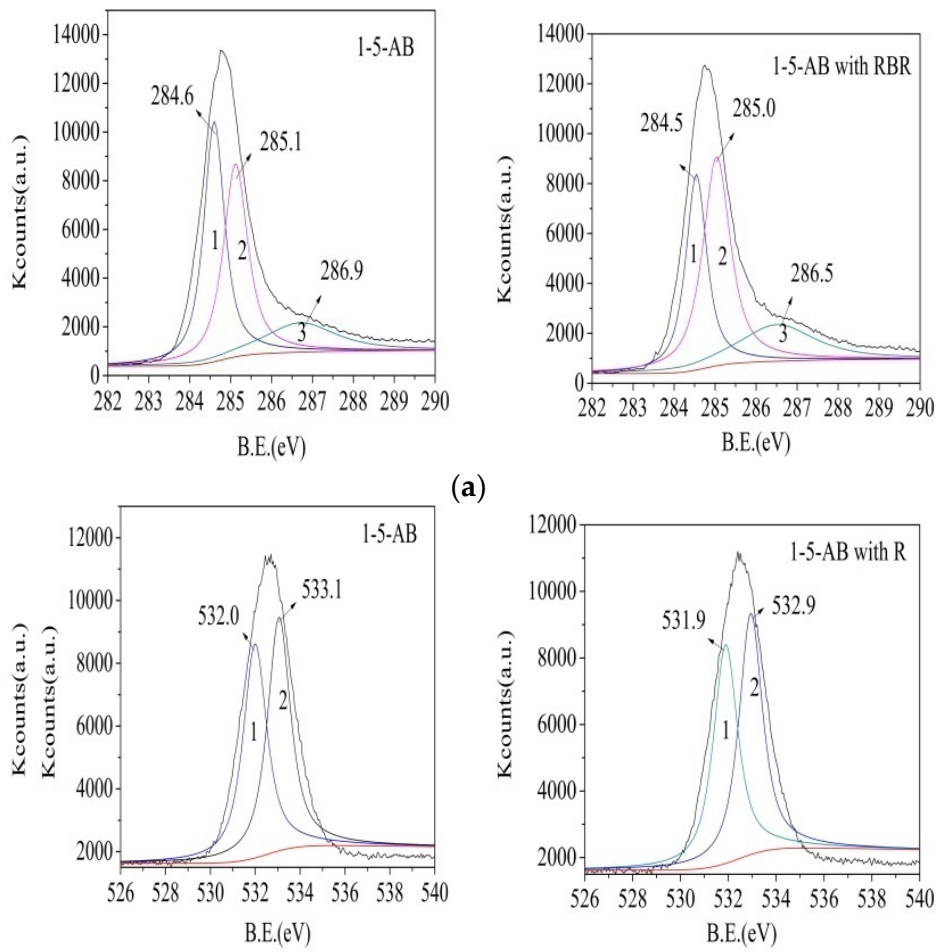

(a)

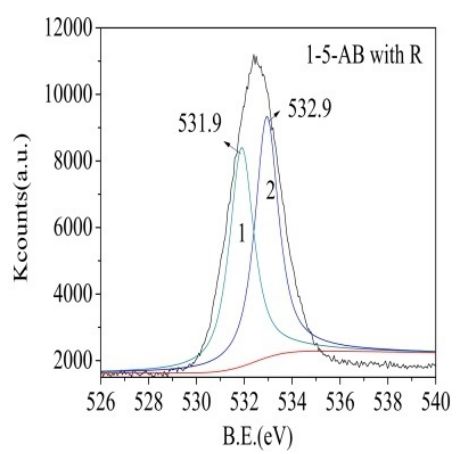

(b)

Figure 10. XPS spectra of $C$ 1s (a) and $O$ 1s (b) of 1-5-AB before and after adsorption of RBR.

\section{Conclusions}

The adsorption of RBR on ATP-modified biochar was investigated. The modified bagasse biochar exhibited better hydrophobicity and affinity for RBR than the pure bagasse biochar. When the content of ATP was within the range of $1 / 3-1$, the modified biochar presented a relatively high adsorption capacity. Moreover, a highly acidic environment was found to be beneficial to adsorption. The pretreatment with ATP not only introduced $\mathrm{Al}_{2} \mathrm{O}_{3}$ and $\mathrm{SiO}_{2}$ particles on the carbon surface within the bagasse biochar matrix but also increased certain oxygen-containing functional groups on the surface. These functional groups served as adsorption sites for RBR in aqueous solutions and greatly improved the RBR removal capability of bagasse biochar. The maximum adsorption capacity of RBR on ATP-modified biochar was not very competitive compared with previously reported adsorbents. Nevertheless, it is low-cost and has high availability and high regeneration ability. Thus, ATP-modified is an efficient adsorbent material for the removal of RBR from aqueous solutions.

Author Contributions: Conceptualization, S.C. and H.-B.H.; Methodology, S.C.; Software, T.W.; Validation, S.C., H.-B.H. and B.-Y.S.; Formal Analysis, S.C.; Investigation, H.-F.W.; Resources, X.-S.W.; Data Curation, S.C., T.W.; Writing-Original Draft Preparation, S.C.; Writing-Review \& Editing, S.C.; Visualization, H.-F.W.; Supervision, M.Z., H.-B.H., B.-Y.S.; Project Administration, H.-B.H., M.Z.; Funding Acquisition, H.-B.H.

Funding: This work was financially supported by the major scientific and technological innovation subject project in Hubei Province, China (No. 2016ACA162).

Acknowledgments: Thanks are due to Professor Mao for Supplying tube furnace in preparation of biochar samples and to Qiao Xiong for valuable discussion.

Conflicts of Interest: The authors declare no conflicts of interest

\section{References}

1. Carneiro, P.A.; Umbuzeiro, G.A.; Oliveira, D.P.; Zanoni, M.V. Assessment of water contamination caused by a mutagenic textile effluent/dyehouse effluent bearing disperse dyes. J. Hazard. Mater. 2016, 174, 694-699. [CrossRef] [PubMed] 
2. Dubey, S.K.; Yadav, R.; Chaturvedi, R.K.; Yadav, R.K.; Sharma, V.K.; Minhas, P.S. Contamination of ground water as a consequence of land disposal of dye waste mixed sewage effluents: A case study of Panipat district of Haryana, India. Bull. Environ. Contam. Toxicol. 2010, 85, 295-300. [CrossRef] [PubMed]

3. Zhou, Q.X.; Wang, M.E. Adsorption-desorption characteristics and pollution behavior of reactive X-3B red dye in four Chinese typical soils. J. Soils Sediments 2010, 10, 1324-1334. [CrossRef]

4. Topac, F.O.; Dindar, E.; Ucaroglu, S.; Baskaya, H.S. Effect of a sulfonated azo dye and sulfanilic acid on nitrogen transformation processes in soil. J. Hazard. Mater. 2009, 170, 1006-1013. [CrossRef] [PubMed]

5. Cao, Z.; Zhang, J.; Zhang, J.; Zhang, H. Degradation pathway and mechanism of Reactive Brilliant Red X-3B in electro-assisted microbial system under anaerobic condition. J. Hazard. Mater. 2017, 329, $159-165$. [CrossRef] [PubMed]

6. Faria, P.C.; Orfao, J.J.; Pereira, M.F. Adsorption of anionic and cationic dyes on activated carbons with different surface chemistries. Water Res. 2004, 38, 2043-2052. [CrossRef] [PubMed]

7. Chen, S.; Zhang, J.; Zhang, C.; Yue, Q.; Li, Y.; Li, C. Equilibrium and kinetic studies of methyl orange and methyl violet adsorption on activated carbon derived from Phragmites australis. Desalination 2010, 252, 149-156. [CrossRef]

8. Soldatkina, L.M.; Sagaidak, E.V. Kinetics of adsorption of water-soluble dyes on activated carbons. J. Water Chem. Technol. 2010, 32, 212-217. [CrossRef]

9. Liu, R.; Zhang, B.; Mei, D.; Zhang, H.; Liu, J. Adsorption of methyl violet from aqueous solution by halloysite nanotubes. Desalination 2011, 268, 111-116. [CrossRef]

10. Zhang, M.; Gao, B.; Varnoosfaderani, S.; Hebard, A.; Yao, Y.; Inyang, M. Preparation and characterization of a novel magnetic biochar for arsenic removal. Bioresour. Technol. 2013, 130, 457-462. [CrossRef] [PubMed]

11. Li, P.; Su, Y.J.; Wang, Y.; Liu, B.; Sun, L.M. Bioadsorption of methyl violet from aqueous solution onto Pu-erh tea powder. J. Hazard. Mater. 2010, 179, 43-48. [CrossRef] [PubMed]

12. Ofomaja, A.E.; Ho, Y.S. Effect of temperatures and $\mathrm{pH}$ on methyl violet biosorption by Mansonia wood sawdust. Bioresour. Technol. 2008, 99, 5411-5417. [CrossRef] [PubMed]

13. Hameed, B.H. Equilibrium and kinetic studies of methyl violet sorption by agricultural waste. J. Hazard. Mater. 2008, 154, 204-212. [CrossRef] [PubMed]

14. Gupta, V.K.; Ali, I.; Saini, V.K.; Gerven, T.V.; der Bruggen, B.V.; Vandecasteele, C. Removal of Dyes from Wastewater Using Bottom Ash. Ind. Eng. Chem. Res. 2005, 44, 3655-3664. [CrossRef]

15. Solpan, D.; Duran, S.; Saraydin, D.; Güven, O. Adsorption of methyl violet in aqueous solutions by poly(acrylamide-co-acrylic acid) hydrogels. Radiat. Phys. Chem. 2003, 66, 117-127. [CrossRef]

16. Doğan, M.; Alkan, M. Removal of methyl violet from aqueous solution by perlite. J. Colloid Interface Sci. 2003, 267, 32-41. [CrossRef]

17. Tong, X.-J.; Li, J.-Y.; Yuan, J.-H.; Xu, R.-K. Adsorption of $\mathrm{Cu}(\mathrm{II})$ by biochars generated from three crop straws. Chem. Eng. J. 2011, 172, 828-834. [CrossRef]

18. Hossain, M.K.; Strezov, V.; Chan, K.Y.; Nelson, P.F. Agronomic properties of wastewater sludge biochar and bioavailability of metals in production of cherry tomato (Lycopersicon esculentum). Chemosphere 2010, 78, 1167-1171. [CrossRef] [PubMed]

19. Yao, Y.; Gao, B.; Inyang, M.; Zimmerman, A.R.; Cao, X.; Pullammanappallil, P.; Yang, L. Biochar derived from anaerobically digested sugar beet tailings: Characterization and phosphate removal potential. Bioresour. Technol. 2011, 102, 6273-6278. [CrossRef] [PubMed]

20. Enders, A.; Hanley, K.; Whitman, T.; Joseph, S.; Lehmann, J. Characterization of biochars to evaluate recalcitrance and agronomic performance. Bioresour. Technol. 2012, 114, 644-653. [CrossRef] [PubMed]

21. Ding, Z.; Hu, X.; Zimmerman, A.R.; Gao, B. Sorption and cosorption of lead (II) and methylene blue on chemically modified biomass. Bioresour. Technol. 2014, 167, 569-573. [CrossRef] [PubMed]

22. Agrafioti, E.; Kalderis, D.; Diamadopoulos, E. Ca and Fe modified biochars as adsorbents of arsenic and chromium in aqueous solutions. J. Environ. Manag. 2014, 146, 444-450. [CrossRef] [PubMed]

23. Zuo, X.; Liu, Z.; Chen, M. Effect of $\mathrm{H}_{2} \mathrm{O}_{2}$ concentrations on copper removal using the modified hydrothermal biochar. Bioresour. Technol. 2016, 207, 262-267. [CrossRef] [PubMed]

24. Yang, G.X.; Jiang, H. Amino modification of biochar for enhanced adsorption of copper ions from synthetic wastewater. Water Res. 2014, 48, 396-405. [CrossRef] [PubMed] 
25. Jiang, J.; $\mathrm{Xu}$, R.-K.; Jiang, T.-Y.; Li, Z. Immobilization of $\mathrm{Cu}(\mathrm{II}), \mathrm{Pb}(\mathrm{II})$ and $\mathrm{Cd}(\mathrm{II})$ by the addition of rice straw derived biochar to a simulated polluted Ultisol. J. Hazard. Mater. 2012, 229-230, 145-150. [CrossRef] [PubMed]

26. Chen, B.; Chen, Z.; Lv, S. A novel magnetic biochar efficiently sorbs organic pollutants and phosphate. Bioresour. Technol. 2011, 102, 716-723. [CrossRef] [PubMed]

27. Liu, N.; Charrua, A.B.; Weng, C.-H.; Yuan, X.; Ding, F. Characterization of biochars derived from agriculture wastes and their adsorptive removal of atrazine from aqueous solution: A comparative study. Bioresour. Technol. 2015, 198, 55-62. [CrossRef] [PubMed]

28. Mahmoud, M.E.; Nabil, G.M.; EI-Mallah, N.M.; Bassiluny, H.I.; Kumar, S.; Abdel-Fattah, T.M. Kinetics, isotherm, and thermodynamic studies of the adsorption of reactive red 195 A dye from water by modified switchgrass Biocha radsorbent. J. Ind. Eng. Chem. 2016, 37, 156-167. [CrossRef]

29. Angin, D.; Kose, T.E.; Selengil, U. production and characterization of activated carbon prepared from safflower seed cake biochar and its ability to absorb reactive dyestuff. Appl. Surface Sci. 2013, 280, 705-710. [CrossRef]

30. Khataee, A.; Kayan, B.; Gholami, P.; Kalderis, D.; Akay, S.; Dinpazhoh, L. Sonocatalytic degradation of Reactive Yellow 39 using synthesized $\mathrm{ZrO}_{2}$ nanoparticles on biochar. Ultrason. Sono Chem. 2017, 39, 540-549. [CrossRef] [PubMed]

31. Li, Y.; Wang, Z.; Xie, X.; Zhu, J.; Li, R.; Qin, T. Removal of Norfloxacin from aqueous solution by clay-biochar composite prepared from potato stem and natural attapulgite. Colloids Surf. A Physicochem. Eng. Aspects 2017, 514, 126-136. [CrossRef]

32. Fan, Q.-H.; Tan, X.-L.; Li, J.-X.; Wang, X.-K.; Wu, W.-S.; Montavon, G. Sorption of Eu(III) on attapulgite studied by batch, XPS, and EXAFS techniques. Environ. Sci. Technol. 2009, 43, 5776-5782. [CrossRef] [PubMed]

33. Mahmoud, D.K.; Salleh, M.A.M.; Karim, W.A.; Idris, A.; Abidin, Z.Z. Batch adsorption of basic dye using acid treated kenaf fibre char: Equilibrium, kinetic and thermodynamic studies. Chem. Eng. J. 2012, 181-182, 449-457. [CrossRef]

34. Xue, Y.; Gao, B.; Yao, Y.; Inyang, M.; Zhang, M.; Zimmerman, A.R.; Ro, K.S. Hydrogen peroxide modification enhances the ability of biochar (hydrochar) produced from hydrothermal carbonization of peanut hull to remove aqueous heavy metals: Batch and column tests. Chem. Eng. J. 2012, 200-202, 673-680. [CrossRef]

35. Mohan, D.; Sarswat, A.; Ok, Y.S.; Pittman, C.U., Jr. Organic and inorganic contaminants removal from water with biochar, a renewable, low cost and sustainable adsorbent-A critical review. Bioresour. Technol. 2014, 160, 191-202. [CrossRef] [PubMed]

36. Zhang, M.; Gao, B.; Yao, Y.; Xue, Y.; Inyang, M. Synthesis of porous MgO-biochar nanocomposites for removal of phosphate and nitrate from aqueous solutions. Chem. Eng. J. 2012, 210, 26-32. [CrossRef]

37. Yao, Y.; Gao, B.; Fang, J.; Zhang, M.; Chen, H.; Zhou, Y.-M.; Creamer, A.E.; Sun, Y.-N.; Yang, L.-Y. Characterization and environmental applications of clay-biochar composites. Chem. Eng. J. 2014, 242, 136-143. [CrossRef]

38. Ahmad, M.; Rajapaksha, A.U.; Lim, J.E.; Zhang, M.; Bolan, N.; Mohan, D.; Vithanage, M.; Lee, S.S.; Ok, Y.S. Biochar as a sorbent for contaminant management in soil and water: A review. Chemosphere 2014, 99, 19-33. [CrossRef] [PubMed]

39. Keiluweit, M.; Nico, P.S.; Johnson, M.G.; Kleber, M. Dynamic molecular structure of plant biomass-derived black carbon (biochar). Enriron. Sci. Technol. 2010, 44, 1247-1253. [CrossRef] [PubMed]

40. Zhang, J.; Wang, Q.; Wang, A. Synthesis and characterization of chitosan-g-poly(acrylic acid)/attapulgite superabsorbent composites. Carbohydr. Polym. 2007, 68, 367-374. [CrossRef]

41. Lammers, K.; Arbuckle-Keil, G.; Dighton, J. FT-IR study of the changes in carbohydrate chemistry of three New Jersey pine barrens leaf litters during simulated control burning. Soil Biol. Biochem. 2009, 41, 340-347. [CrossRef]

42. Özçimen, D.; Ersoy-Meriçboyu, A. Characterization of biochar and bio-oil samples obtained from carbonization of various biomass materials. Renew. Energy 2010, 35, 1319-1324. [CrossRef]

43. Xu, R.-K.; Xiao, S.-C.; Yuan, J.-H.; Zhao, A.-Z. Adsorption of methyl violet from aqueous solutions by the biochars derived from crop residues. Bioresour. Technol. 2011, 102, 10293-10298. [CrossRef] [PubMed]

44. Park, J.H.; Ok, Y.S.; Kim, S.H.; Cho, J.S.; Heo, J.S.; Delaune, R.D.; Seo, D.C. Competitive adsorption of heavy metals onto sesame straw biochar in aqueous solutions. Chemosphere 2016, 142, 77-83. [CrossRef] [PubMed] 
45. Bazrafshan, A.A.; Hajati, S.; Ghaedi, M. Synthesis of regenerable $\mathrm{Zn}(\mathrm{OH})_{2}$ nanoparticle-loaded activated carbon for the ultrasound-assisted removal of malachite green: Optimization, isotherm and kinetics. RSC Adv. 2015, 5, 79119-79128. [CrossRef]

46. Li, X.; Xie, X.; Luo, H.; Li, L.; Li, Z.; Xue, Z.; Li, W. Adsorption of reactive yellow X-RG and reactive brilliant red $\mathrm{X}-3 \mathrm{~B}$ onto cucurbit[8]uril and cucurbit[6]uril: Effect factors, adsorption behavior and mechanism study. J. Colloid Interface Sci. 2017, 498, 31-46. [CrossRef] [PubMed]

47. Yan, Z.; Li, G.; Mu, L.; Tao, S. Pyridine-functionalized mesoporous silica as an efficient adsorbent for the removal of acid dyestuffs. J. Mater. Chem. 2006, 16, 1717-1725. [CrossRef]

48. Cao, C.; Xiao, L.; Chen, C.; Shi, X.; Cao, Q.; Gao, L. In situ preparation of magnetic $\mathrm{Fe}_{3} \mathrm{O}_{4} /$ chitosan nanoparticles via a novel reduction-precipitation method and their application in adsorption of reactive azo dye. Powder Technol. 2014, 260, 90-97. [CrossRef]

49. Song, Z.; Chen, L.; Hu, J.; Richards, R. NiO(111) nanosheets as efficient and recyclable adsorbents for dye pollutant removal from wastewater. Nanotechnology 2009, 20, 275707. [CrossRef] [PubMed]

50. Hu, J.; Song, Z.; Chen, L.; Yang, H.; Li, J.; Richards, R. Adsorption properties of MgO(111) nanoplates for the dye pollutants from wastewater. J. Chem. Eng. Data 2010, 55, 3742-3748. [CrossRef]

51. Wu, X.; Wu, D.; Fu, R. Studies on the adsorption of reactive brilliant red X-3B dye on organic and carbon aerogels. J. Hazard. Mater. 2007, 147, 1028-1036. [CrossRef] [PubMed]

52. Zhang, C.; Yang, S.; Chen, H.; He, H.; Sun, C. Adsorption behavior and mechanism of reactive brilliant red $\mathrm{X}-3 \mathrm{~B}$ in aqueous solution over three kinds of hydrotalcite-like LDHs. Appl. Surf. Sci. 2014, 301, 329-337. [CrossRef]

53. Liu, W.-J.; Zeng, F.-X.; Jiang, H.; Zhang, X.-S. Preparation of high adsorption capacity bio-chars from waste biomass. Bioresour. Technol. 2011, 102, 8247-8252. [CrossRef] [PubMed]

54. Li, M.; Liu, Q.; Guo, L.; Zhang, Y.; Lou, Z.; Wang, Y.; Qian, G. Cu(II) removal from aqueous solution by Spartina alterniflora derived biochar. Bioresour. Technol. 2013, 141, 83-88. [CrossRef] [PubMed]

55. Valdes, H.; sanchez-Polo, M.; Rivera-Utrilla, J.; Zaror, C.A. Effect of ozone treatment on surface properties of activated carbon. Langmuir 2002, 18, 2111-2116. [CrossRef]

56. Zhu, X.; Tsang, D.C.; Chen, F.; Li, S.; Yang, X. Ciprofloxacin adsorption on graphene and granular activated carbon: Kinetics, isotherms, and effects of solution chemistry. Environ. Technol. 2015, 36, 3094-3102. [CrossRef] [PubMed] 